\title{
Strength and Durability Performance of Alkali-Activated Rice Husk Ash Geopolymer Mortar
}

\author{
Yun Yong Kim, ${ }^{1}$ Byung-Jae Lee, ${ }^{1}$ Velu Saraswathy, ${ }^{2}$ and Seung-Jun Kwon ${ }^{3}$ \\ ${ }^{1}$ Department of Civil Engineering, Chungnam National University, Daejeon 305-764, Republic of Korea \\ ${ }^{2}$ Corrosion and Materials Protection Division, CSIR-Central Electrochemical Research Institute, Karaikudi, India \\ ${ }^{3}$ Department of Civil Engineering, Hannam University, Daejeon 306-791, Republic of Korea \\ Correspondence should be addressed to Seung-Jun Kwon; jjuni98@hannam.ac.kr
}

Received 2 July 2014; Revised 18 September 2014; Accepted 19 September 2014; Published 23 November 2014

Academic Editor: Yinghai Wu

Copyright (C) 2014 Yun Yong Kim et al. This is an open access article distributed under the Creative Commons Attribution License, which permits unrestricted use, distribution, and reproduction in any medium, provided the original work is properly cited.

\begin{abstract}
This paper describes the experimental investigation carried out to develop the geopolymer concrete based on alkali-activated rice husk ash (RHA) by sodium hydroxide with sodium silicate. Effect on method of curing and concentration of $\mathrm{NaOH}$ on compressive strength as well as the optimum mix proportion of geopolymer mortar was investigated. It is possible to achieve compressive strengths of $31 \mathrm{~N} / \mathrm{mm}^{2}$ and $45 \mathrm{~N} / \mathrm{mm}^{2}$, respectively for the $10 \mathrm{M}$ alkali-activated geopolymer mortar after 7 and 28 days of casting when cured for 24 hours at $60^{\circ} \mathrm{C}$. Results indicated that the increase in curing period and concentration of alkali activator increased the compressive strength. Durability studies were carried out in acid and sulfate media such as $\mathrm{H}_{2} \mathrm{SO}_{4}, \mathrm{HCl}_{2} \mathrm{Na}_{2} \mathrm{SO}_{4}$, and $\mathrm{MgSO}_{4}$ environments and found that geopolymer concrete showed very less weight loss when compared to steam-cured mortar specimens. In addition, fluorescent optical microscopy and X-ray diffraction (XRD) studies have shown the formation of new peaks and enhanced the polymerization reaction which is responsible for strength development and hence RHA has great potential as a substitute for ordinary Portland cement concrete.
\end{abstract}

\section{Introduction}

The production of one ton of cement emits approximately one ton of carbon dioxide to the atmosphere which leads to global warming conditions $[1,2]$. It is important to reduce the $\mathrm{CO}_{2}$ emission through usage of waste materials like fly ash (FA), silica fume (SF), ground granulated blast furnace slag (GGBFS), and rice hush ask (RHA), which contributes to the improvement of the binder properties such as long-term strength, permeability, and durability [3-5]. The continuous increase in the generation of waste materials outlines a challenge to the investigators to propose solutions to its reuse $[6,7]$. What is more, it is a habitual practice to incorporate these materials to hydraulic binders as a solution to their final confinement; besides that, in many occasions, the incorporation results in improvements of the properties of the resulting material as much in mechanical properties and durability $[8,9]$ Among the supplementary cementitious materials FA and GGBFS are widely used for high volume replacement for their enhancement of engineering properties [10, 11]; however, the other materials can be considered for reuse or reutilization of resources.

Rice husk constitutes $20 \%$ of the 500 million tons of paddy produced in the world. $75 \%$ organic volatile matter and the balance $25 \%$ of the weight of this husk are converted into ash during the burning process known as rice husk ash. RHA contains very high amount of silica content and is found to be amorphous in nature. The amorphous silica contained in RHA can react with cementitious binders to perform pozzolanic activity [12]. Geopolymer is an aluminosilicate material that exhibits very good strength, hardness, and chemical stability [13]. The chemical composition of geopolymer is similar to that of zeolite, but it shows an amorphous microstructure. Geopolymer binders have been reported as being acidresistant [14], economical, environmentally-friendly, and more absorbent of liquids and produce a highly durable product [15]. Kusbiantoro et al. studied the effect of FA based geopolymer concrete and found that elevated temperature is suitable for rapid dissolution of silicate monomer and oligomer from microwave incinerated RHA surfaces, which supports 


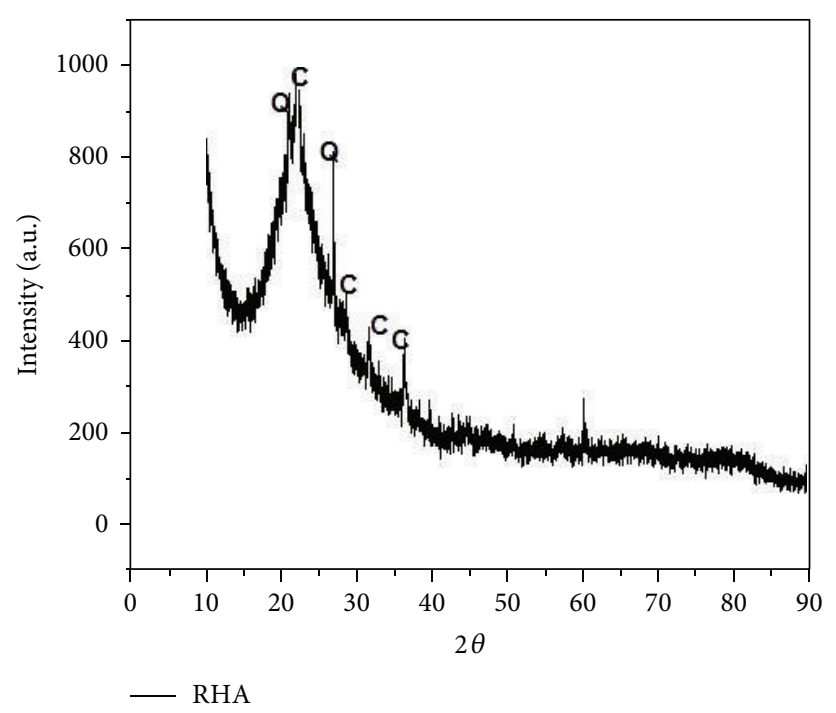

FIGURE 1: XRD pattern of RHA ( $\mathrm{C}=$ cristobalite; $\mathrm{Q}=$ quartz $)$.

TABLE 1: Composition of alkali activators used for the investigation.

\begin{tabular}{lccccccc}
\hline \multirow{2}{*}{ Key } & \multicolumn{3}{c}{ Mass ratio of solution $(1: 2.5)$} & \multicolumn{3}{c}{ Composition of GP liquor } \\
& Na-silicate & $\mathrm{NaOH}$ & Total & $\mathrm{Na}_{2} \mathrm{O}$ & $\mathrm{SiO}_{2}$ & $\mathrm{H}_{2} \mathrm{O}$ & \multicolumn{2}{c}{ Total } \\
\hline $7 \mathrm{M}$ & 3.10 & 1.24 & 4.34 & 0.68 & 1.34 & 2.32 \\
$8 \mathrm{M}$ & 3.18 & 1.27 & 4.45 & 0.72 & 1.38 & 2.35 \\
$9 \mathrm{M}$ & 3.23 & 1.29 & 4.52 & 0.76 & 1.40 & 2.36 \\
$10 \mathrm{M}$ & 3.30 & 1.32 & 4.62 & 0.81 & 1.43 & 2.35 \\
\hline
\end{tabular}

the formation of supersaturated aluminosilicate solution in geopolymer system [16].

So far a systematic investigation of strength and microstructural and durability properties of RHA geopolymer concrete is very scarce. Hence, the present investigation aims to study the effect of RHA in making geopolymer concrete with different concentrations of sodium hydroxide with reference to strength characteristics, temperature effect, and microstructural and durability properties.

\section{Experimental}

2.1. Materials and Method. Ordinary Portland cement (OPC) conforming to ASTM C150-Type I was used for this study. River sand passing through $2.36 \mathrm{~mm}$ sieve having fineness modulus of 2.60 conforming to grading zone III was used for this investigation. The specific gravity and water absorption of fine aggregates were 2.41 and $0.5 \%$, respectively. Sodium silicate was used as an alkali activator with sodium hydroxide solutions varying from 7 to 10 molar concentrations as shown in Table 1 which were used for the investigation.

RHA was obtained by burning rice husk at controlled temperature $\left(650^{\circ} \mathrm{C}\right.$ to $\left.700^{\circ} \mathrm{C}\right)$ to achieve amorphous silica. $\mathrm{XRD}$ pattern of RHA used is given in Figure 1. Figure 1 shows that the diffraction peaks at $20.75^{\circ}$ and $26.8^{\circ}$ correspond to quartz and that other peaks at $21.7^{\circ}, 28.9^{\circ}, 31.2^{\circ}$, and $36^{\circ}$ correspond to cristobalite. RHA was found to be in amorphous form between $2 \theta$ angle of $14.8^{\circ}$ and $27.1^{\circ}$. The amorphous or crystalline formation of silica depends upon the temperature of burning and the method of ash production [17]. The chemical composition and physical properties of OPC and RHA are presented in Table 2.

2.2. Mix Design and Curing. Geopolymer mortars were made with RHA : sand ratio $1: 2$. Sodium hydroxide concentrations used were $7,8,9$, and 10 molar, and the sodium silicate to sodium hydroxide ratio $2.5 \%$ by mass was used. The mixing, casting, and curing procedures adopted for making geopolymer mortar are given in Figure 2. In thermal curing, the specimens were kept in oven at $60^{\circ} \mathrm{C}$ for $24 \mathrm{hrs}$ and then were kept at room temperature over a period of 7,14 , and 28 days. For comparison, OPC mortar was cast with $0.45 \mathrm{~W} / \mathrm{C}$ ratio and subjected to steam curing at $85 \% \mathrm{RH}$ over a period of 7, 14, and 28 days. Then both the specimens were subjected to various types of investigations such us compression test, fluorescence microscopy, elevated temperature study, acid and sulfate resistance test, and ultrasonic pulse velocity test.

2.3. Compression Test. The compressive strength is one of the most important properties of mortar. Specimens of size of $100 \times 100 \times 100 \mathrm{~mm}$ cubes were cast with geopolymer mortar with different concentrations of $\mathrm{NaOH}$. The specimens were subjected to ambient and thermal curing. For comparison, OPC mortar cubes were also cast and subjected to steam 


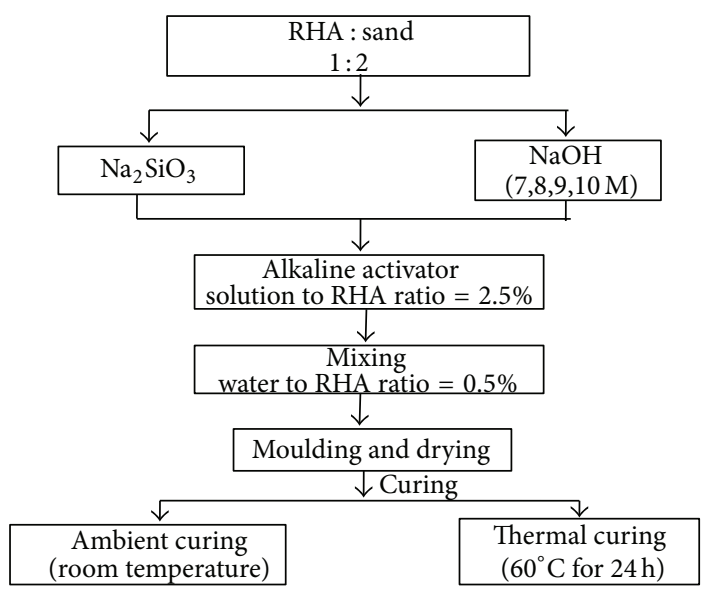

FIGURE 2: The mixing, casting, and curing procedures adopted for making geopolymer.

TABLE 2: Chemical composition and physical properties of OPC and RHA.

\begin{tabular}{lcc}
\hline Compound (\%) & OPC & RHA \\
\hline $\mathrm{SiO}_{2}$ & 20.90 & 90.79 \\
$\mathrm{Al}_{2} \mathrm{O}_{3}$ & 5.40 & 2.22 \\
$\mathrm{Fe}_{2} \mathrm{O}_{3}$ & 4.60 & 0.80 \\
$\mathrm{CaO}$ & 63.50 & 0.92 \\
$\mathrm{MgO}$ & 0.60 & 0.47 \\
$\mathrm{SO}_{3}$ & 2.60 & - \\
$\mathrm{Na}_{2} \mathrm{O}$ & 0.15 & 0.50 \\
$\mathrm{~K}_{2} \mathrm{O}$ & 0.25 & 0.30 \\
LOI & 2.00 & 4.00 \\
Specific gravity & 3.15 & 2.26 \\
Average particle size $(\mu)$ & 45.34 & 25.42 \\
Colour & Grey & Grey \\
\hline
\end{tabular}

curing at $85 \% \mathrm{RH}$ for 7,14 , and 28 days. At the end of curing, compression tests were conducted. For each system, triplicate specimens were cast. The cubes were tested in the compression testing machine of $60 \mathrm{~T}$ capacity. The load was applied at a rate of $140 \mathrm{kN} / \mathrm{min}$. The ultimate load at failure was noted.

2.4. Fluorescence Microscopy and Capillary Flow Analysis. Fluorescence microscopy is an important tool to analyze concrete and mortar and other related building materials like stones, bricks, and so forth. Semitransparent thin sections as thin as $20 \mu \mathrm{m}$ of concrete can be analyzed by fluorescence microscopy in bright field or polarized light mode with or without tint plate. Additionally, the thin sections can be impregnated with the fluorescent epoxy for fluorescence microscopy. Examination with fluorescence light microscopy gives information about the porosity of the material. A dense area of the material appears in dark colour, while porous areas appear in light colour. Bright field microscopy reveals general information about the composition and structure of the material. Polarized light helps to identify the crystallinity and composition of the minerals. Microscopical examination of concrete helps to assure quality and to evaluate the durability and deterioration processes.

2.5. Capillary Flow Analysis. Cement mortar and geopolymer mortar specimens were cut into $1 \mathrm{Cm} \times 1 \mathrm{Cm} \times 1 \mathrm{Cm}$ pieces and were treated with ethanol/acetone and kept in oven at $100^{\circ} \mathrm{C}$ for 24 hours to remove the free moisture present in the pores. Then the specimens were subjected to capillary flow analysis using capillary flow porometer (PMI Inc., USA) under a pressure of 250 psi to identify the pore size distribution and pore diameter of the samples.

2.6. Elevated Temperature Study. Muffle furnace was used for this study. Specimens were subjected to heat at temperatures of $300^{\circ} \mathrm{C}, 500^{\circ} \mathrm{C}$, and $700^{\circ} \mathrm{C}$ at an incremental rate of $4^{\circ} \mathrm{C}$ per minute from room temperature. The temperature was sustained for 1 hour. Then the specimens were allowed to cool down for 24 hours at room temperature inside the furnace and tested for their compressive strengths after 7, 14, and 28 days.

2.7. Acid and Sulfate Resistance Test. Geopolymer mortars were subjected to acid and sulfate resistance test by immersing the specimens in $5 \% \mathrm{HCl}, 5 \% \mathrm{H}_{2} \mathrm{SO}_{4}, 5 \% \mathrm{Na}_{2} \mathrm{SO}_{4}$, and $5 \% \mathrm{MgSO}_{4}$ over a period of 28 days and the weight loss was calculated. $5 \%$ is chosen on the basis of the aggressiveness when compared to $10 \%$ concentration.

2.8. Ultrasonic Pulse Velocity (UPV) Test. UPV measurements were carried out for all the geopolymer mortar cubes and the result was compared to control specimens. The velocity of an ultrasonic pulse is influenced by the properties of concrete which determines the elastic stiffness and mechanical strength. Hence, each material has typical ultrasonic pulse velocities. These velocities can be correlated with the material properties. Comparatively, higher velocity is obtained when concrete quality is good in terms of density, 
TABLE 3: 7-, 14-, and 28-day compressive strength of geopolymer and control mortar.

\begin{tabular}{|c|c|c|c|c|c|c|c|c|c|}
\hline \multirow{4}{*}{$\begin{array}{l}\text { Number } \\
\text { of days }\end{array}$} & \multicolumn{9}{|c|}{ Compressive strength of geopolymer mortar (MPa) } \\
\hline & \multicolumn{9}{|c|}{ Concentration of alkali activator/curing } \\
\hline & \multicolumn{2}{|c|}{$7 \mathrm{M}$} & \multicolumn{2}{|c|}{$8 \mathrm{M}$} & \multicolumn{2}{|c|}{$9 \mathrm{M}$} & \multicolumn{2}{|c|}{$10 \mathrm{M}$} & \multirow{2}{*}{ Control } \\
\hline & A & $\mathrm{T}$ & A & $\mathrm{T}$ & A & $\mathrm{T}$ & A & $\mathrm{T}$ & \\
\hline 7 & 9 & 19 & 13 & 21 & 16 & 22 & 17 & 26 & 10 \\
\hline 14 & 19 & 27 & 19 & 28 & 22 & 30 & 23 & 31 & 19 \\
\hline 28 & 34 & 40 & 36 & 41 & 38.5 & 43 & 40.7 & 45 & 25 \\
\hline
\end{tabular}

A: ambient curing; T: Thermal curing.

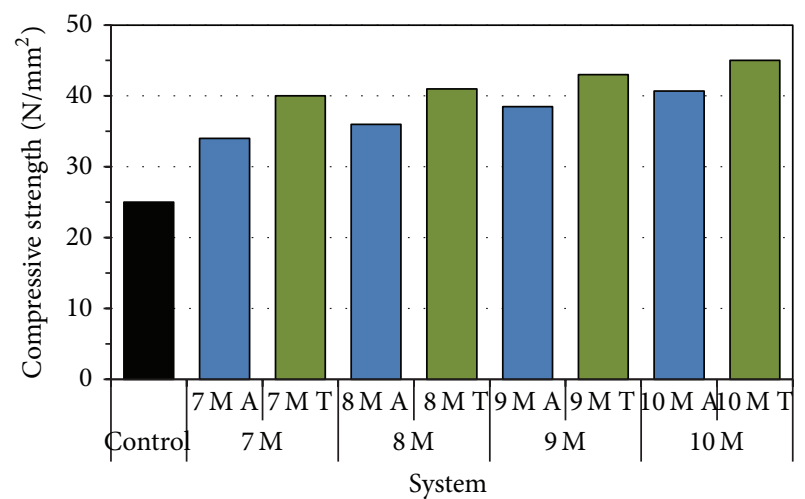

FIGURE 3: Compressive strength of geopolymer and control mortar at 28 days.

uniformity, and homogeneity. UPV measurements were also used to measure the defects and to assess the deterioration and soundness of the concrete [18].

\section{Results and Discussion}

3.1. Compressive Strength Test. 7-, 14-, and 28-day compressive strength that is obtained for geopolymer and control mortar cubes was reported in Table 3. From Table 3 it is observed that the compressive strength was found to increase with the increase in the curing period. Figure 3 depicts the compressive strength of geopolymer and control mortar after 28 days of curing. From the figure it is observed that geopolymer mortar has shown higher compressive strength than control specimens. Thermally cured specimens have shown higher compressive strengths of $15 \%$ (7 M), 12.2\% (8 M), $10.47 \%(9 \mathrm{M})$ and $9.6 \%(10 \mathrm{M})$, and $37.5 \%(7 \mathrm{M}), 39 \%(8 \mathrm{M})$, $41.9 \%(9 \mathrm{M}), 44.4 \%(10 \mathrm{M})$ after 28 days than the ambient cured and control samples. Among all, $10 \mathrm{M}$ alkali-activated geopolymer concrete with thermal curing has shown higher compressive strength due to the presence of heat which accelerated the strength due to the strong $\mathrm{Si}-\mathrm{O}-\mathrm{Al}$ bond formation.

3.2. Fluorescence Microscopy. 3D images of fluorescence micrographs taken for different molar concentrations of geopolymer mortars were given in Figures 4(a)-4(e). From the figures, it was found that as the concentration increases the height of the peak formation was found to be narrow and closer indicating the denser packing and as the concentration decreases the peaks were found to be short and broader indicating the porous nature of the mortar. At higher concentration, the particle packing was found to be dense and compact which is responsible for pore size refinement indicating the homogeneity of the geopolymer mortar.

3.3. Capillary Flow Analysis. Figures 5(a) and 5(b) show the pore size distribution versus diameter of control and geopolymer $(10 \mathrm{M})$ mortar. From the figure, it is observed that the geopolymer particles have lesser and uniform pore size distribution when compared to control mortar. The average pore diameter was ranging from 0.2 to 485 and from 0.08 to $274 \mu \mathrm{m}$ for control and geopolymer systems, respectively. From the data, it was observed that nearly $55 \%$ reduction in pore size distribution was observed for geopolymer mortar than the control mortar. This observation clearly confirmed the pore blocking effect due to the increasing in concentration of $10 \mathrm{M} \mathrm{NaOH}$.

3.4. Elevated Temperature Study. Elevated temperature studies were carried out at $300^{\circ} \mathrm{C}$ and $500^{\circ} \mathrm{C}$ and at $700^{\circ} \mathrm{C}$ and $900^{\circ} \mathrm{C}$ for all the systems and represented in Figures $6(\mathrm{a})-6(\mathrm{~d})$. From the studies, it is found that the compressive strength was found to decrease with the increase in temperatures due to the accelerated drying. Initially at low temperature $\left(300^{\circ} \mathrm{C}\right)$ the strength loss of geopolymer mortars was observed to be very less due to the evaporation of surface moisture content. But the control specimens have lost $88 \%$ of their original compressive strengths at $300^{\circ} \mathrm{C}$, and, beyond $300^{\circ} \mathrm{C}$, the specimens got crumbled into powder indicating the total failure of the samples. As the temperature increases from $300^{\circ} \mathrm{C}$ to $900^{\circ} \mathrm{C}$, evaporation of free water content was rapid and when it reaches the maximum limit, it creates pressure inside the geopolymer mortar, which leads to internal cracking due to vapour effect [19] that ultimately decreased the compressive of the specimens [20]. The presence of silicates caused swelling effect due to the thermal expansion which reduced the compressive strength at high temperature exposure [21].

3.5. Acid and Sulfate Resistance Test. Figures 7, 8, 9, 10, 11, 12,13 , and 14 indicate the acid and sulfate resistance studies carried out for different geopolymer mortar and control 


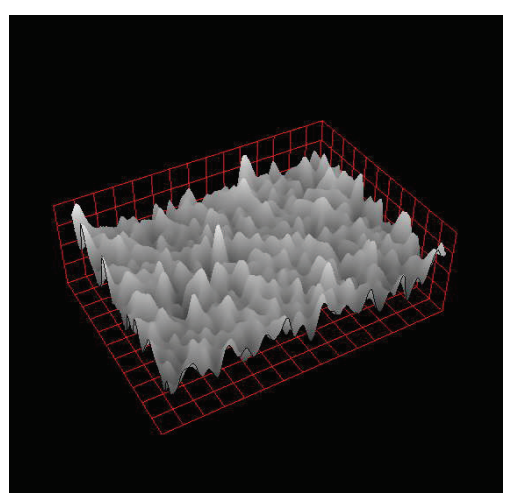

(a) $10 \mathrm{M}$ geopolymer mortar

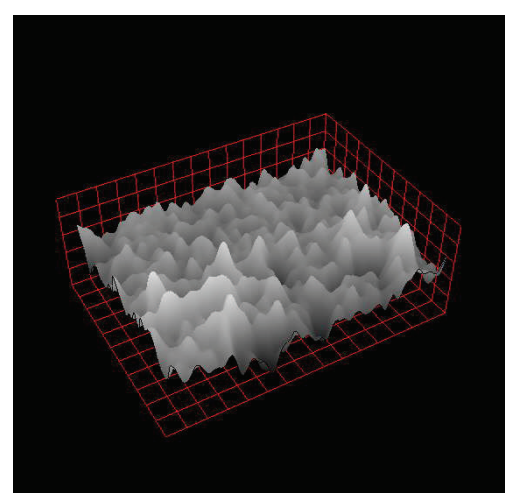

(b) $9 \mathrm{M}$ geopolymer mortar

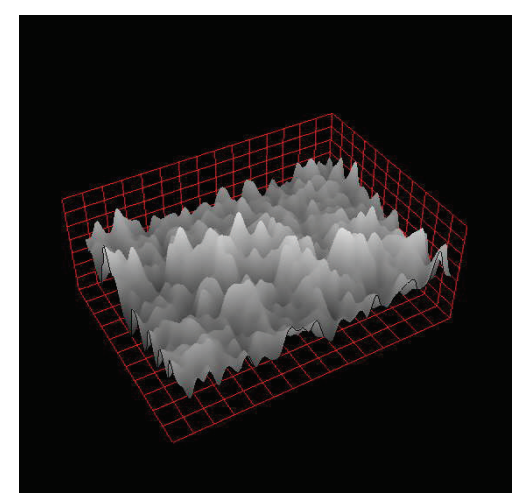

(c) $8 \mathrm{M}$ geopolymer mortar

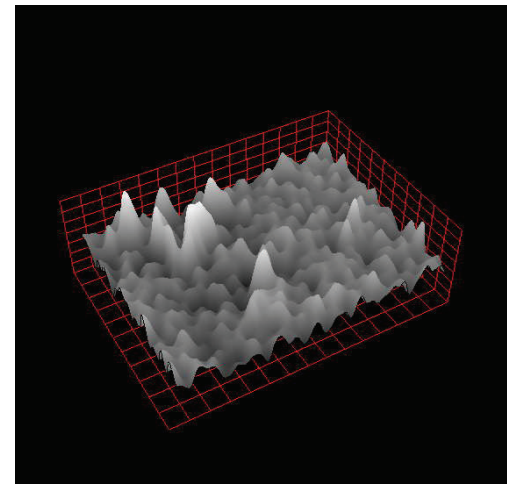

(d) 7 M geopolymer mortar

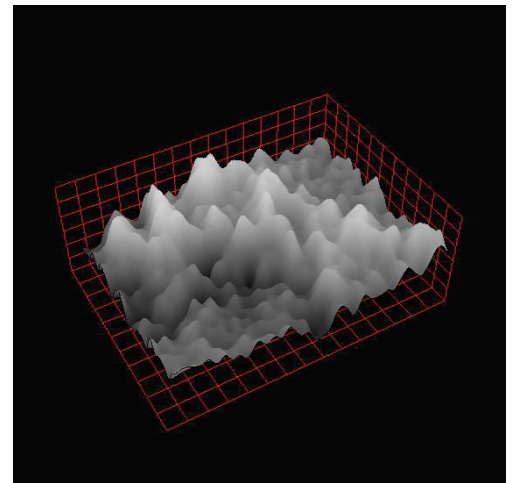

(e) Control mortar

FIGURE 4: 3D optical microscopic images of geopolymer and control mortars.

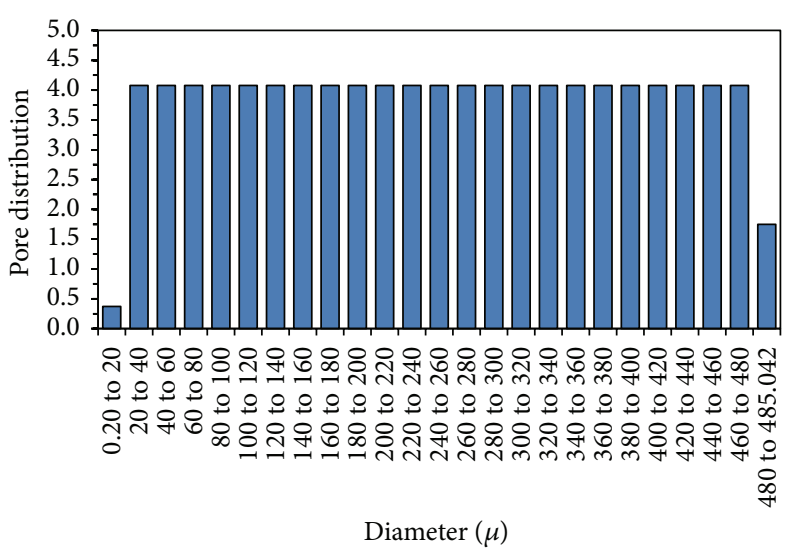

(a)

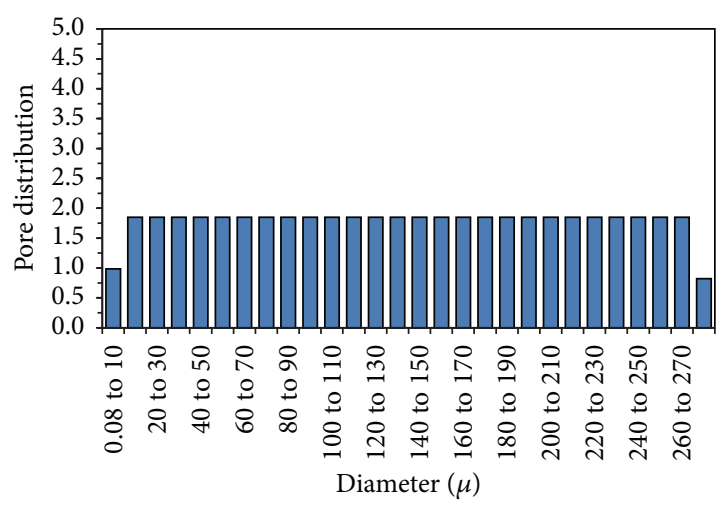

(b)

FIgURE 5: (a) Pore size distribution versus diameter of cement mortar. (b) Pore size distribution versus diameter of geopolymer mortar.

specimens. From the studies, it is found that the percentage weight loss was found to be more than $22 \%$ and $8 \%$ in $\mathrm{H}_{2} \mathrm{SO}_{4}$ and $\mathrm{HCl}$ media, respectively. This weight loss is due to the presence of active calcium hydroxide. When compared to acid and sulfate immersion, acid is found to be aggressive, indicating higher weight loss. In general geopolymer mortar has excellent acid and sulfate resistance due to the absence of cement $\left(\mathrm{Ca}(\mathrm{OH})_{2}\right)$. In acid and sulfate exposure, geopolymer mortars have shown weight gain of up to $2.5 \%$ after 28 days of exposure, which is due to scale formation in acid and deposition of white powder formation in sulphate exposure on the surface of the specimens $[22,23]$.

3.6. Ultrasonic Pulse Velocity Test. UPV measurements were carried out for higher weight loss observed specimens. Figure 15 shows the UPV measurements taken for thermal cured specimens immersed in $5 \% \mathrm{H}_{2} \mathrm{SO}_{4}$ medium over a period of 4 weeks of exposure. Higher velocity reduction was observed 


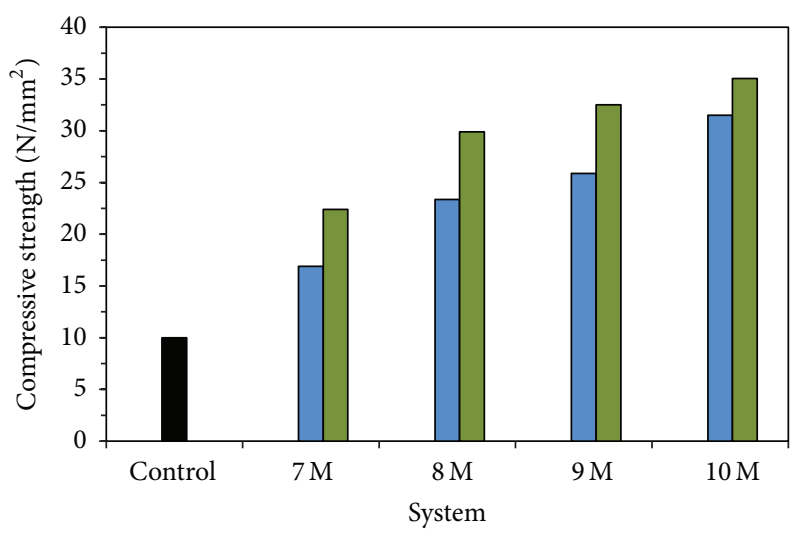

(a) Compressive strength at $300^{\circ} \mathrm{C}$

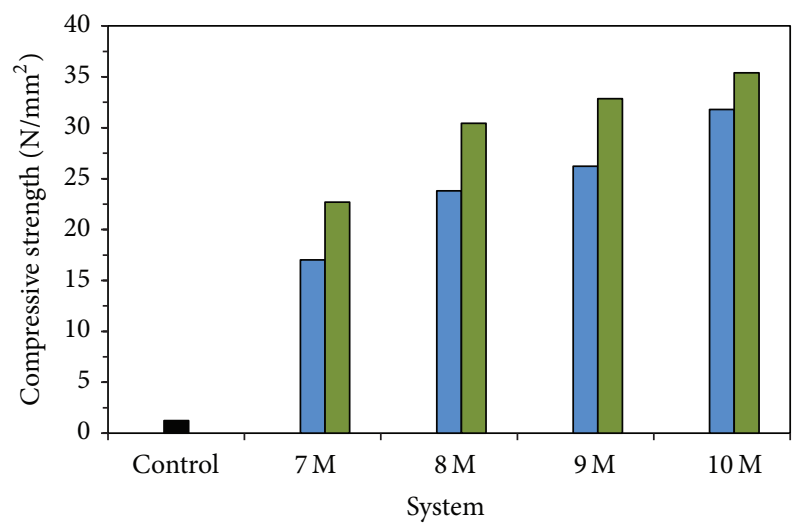

Control

Ambient curing

$\square$ Thermal curing

(c) Compressive strength at $700^{\circ} \mathrm{C}$

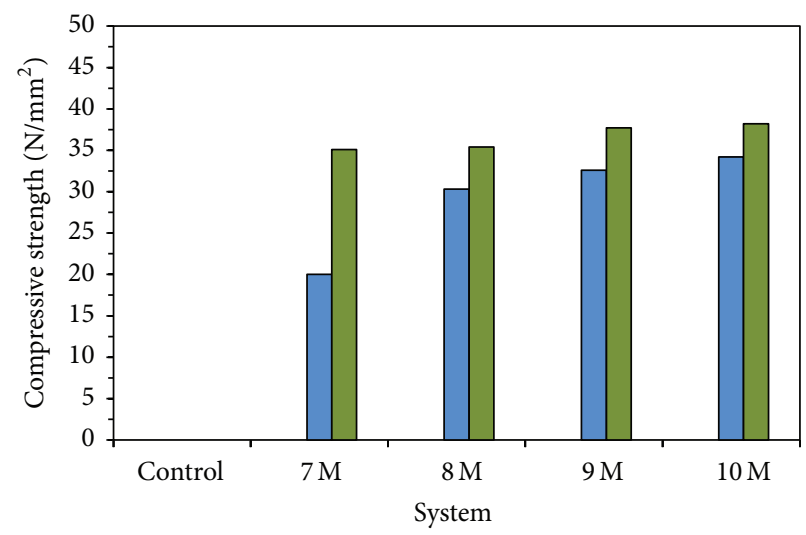

(b) Compressive strength at $500^{\circ} \mathrm{C}$

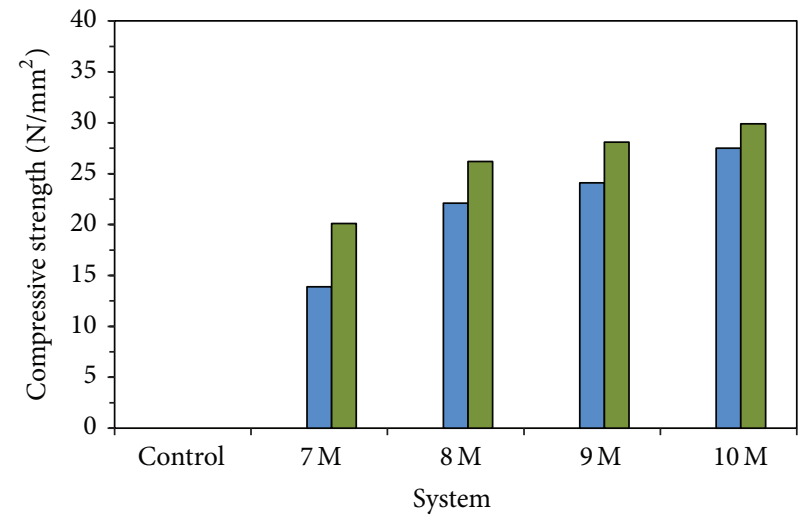

Control

$\square$ Ambient curing

$\square$ Thermal curing

(d) Compressive strength at $900^{\circ} \mathrm{C}$

FIGURE 6: Compressive strength of various systems at elevated temperature.

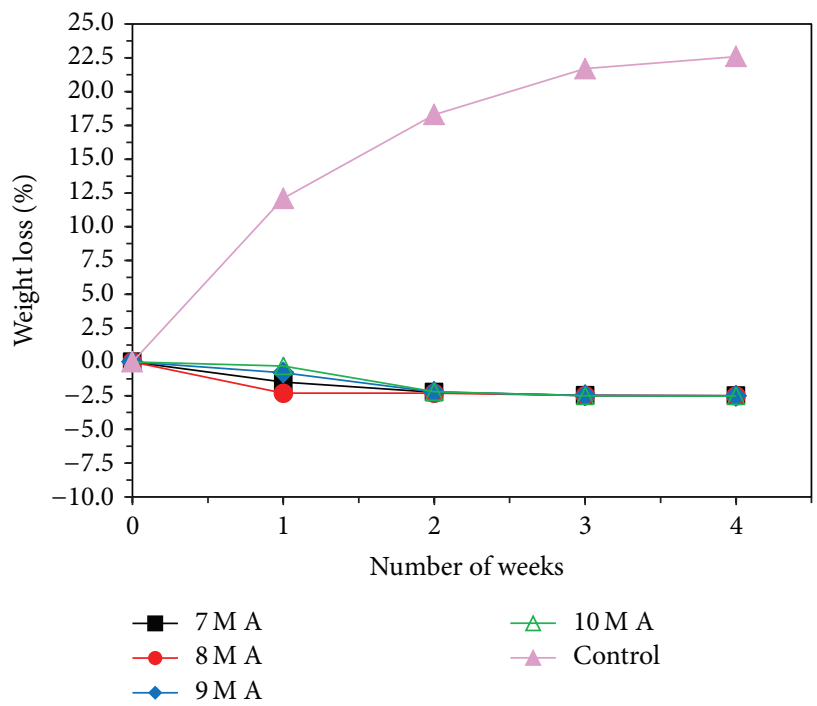

(a) Ambient curing

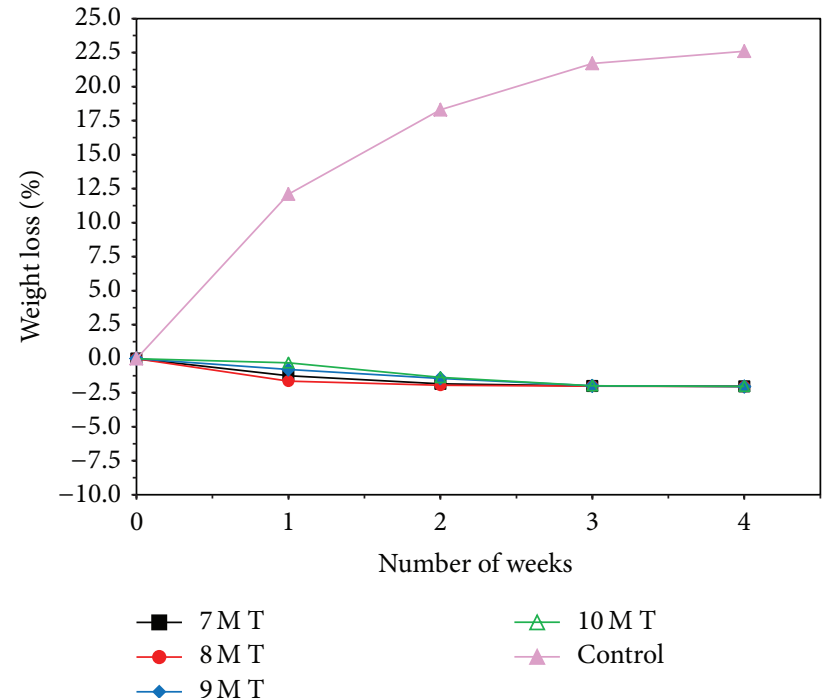

(b) Thermal curing

FIgURE 7: Weight loss for specimens immersed in $5 \% \mathrm{H}_{2} \mathrm{SO}_{4}$ after 28 days. 


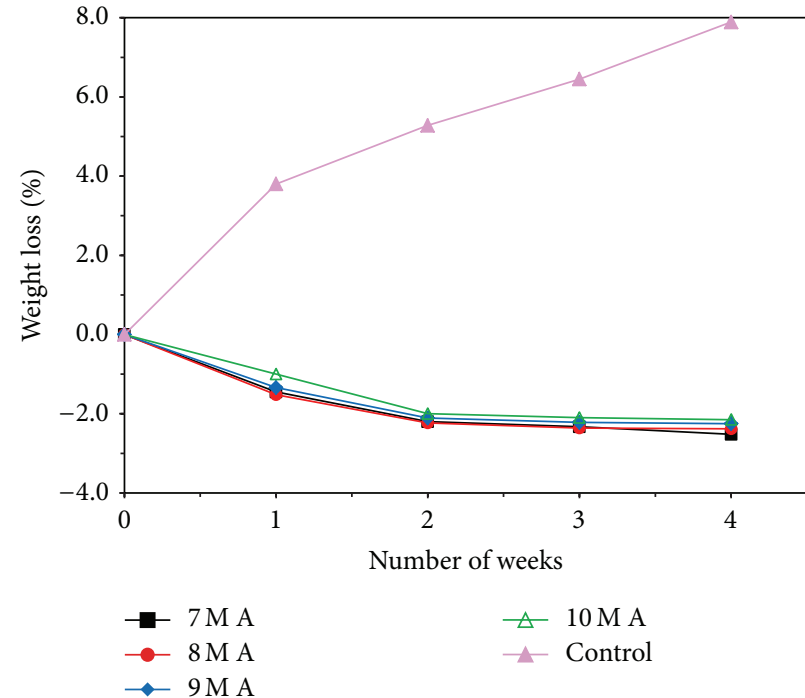

(a) Ambient curing

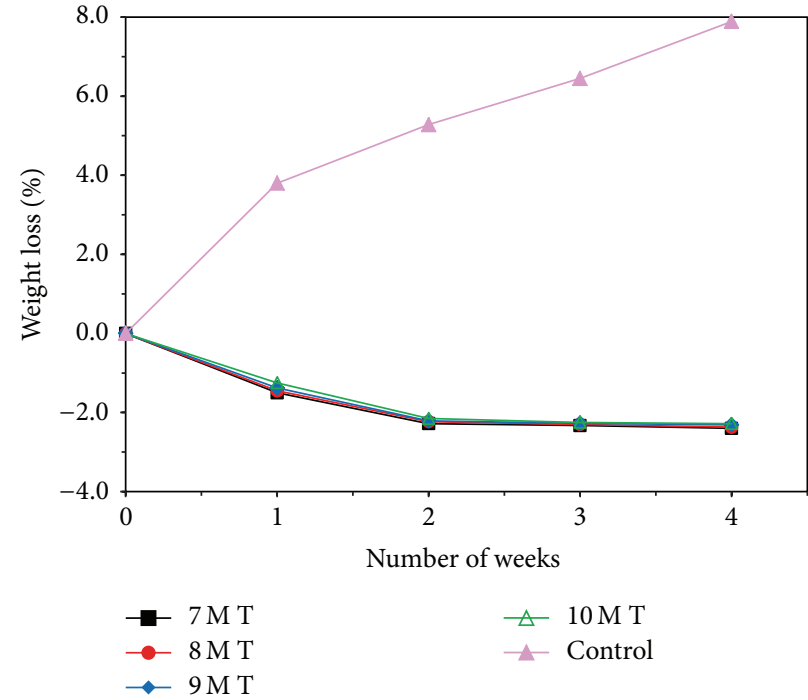

(b) Thermal curing

FIGURE 8: Weight loss for specimens immersed in 5\% $\mathrm{HCl}$ after 28 days.

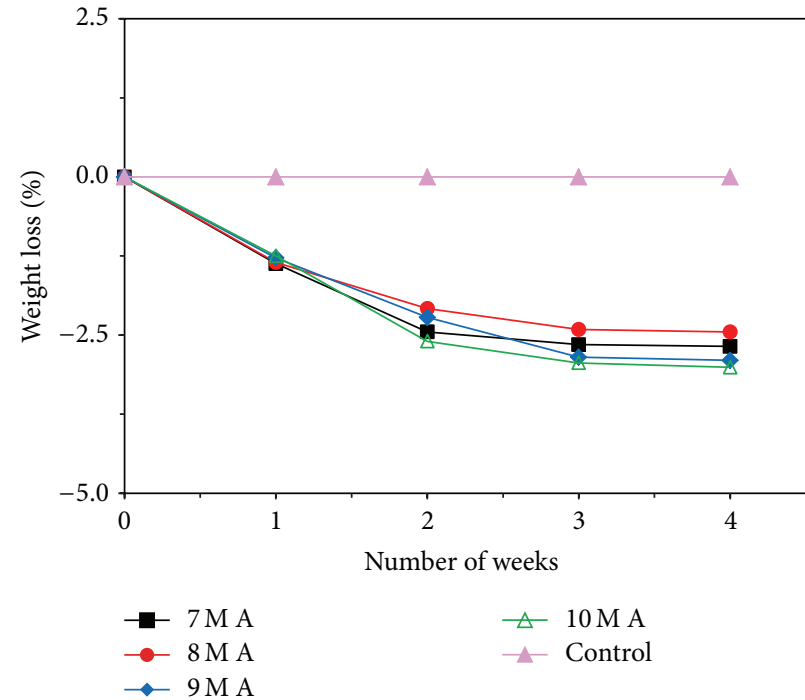

(a) Ambient curing

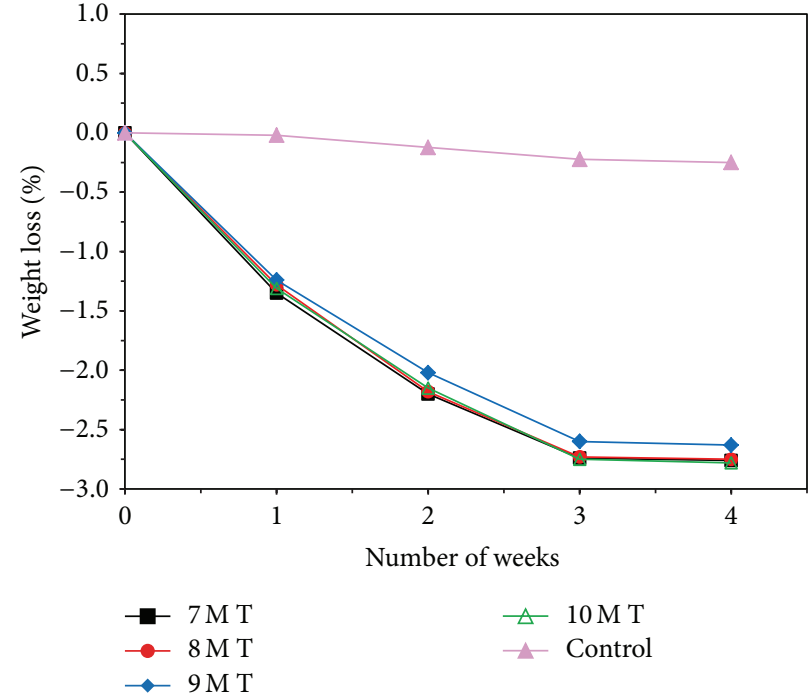

(b) Thermal curing

Figure 9: Weight loss for specimens immersed in 5\% $\mathrm{MgSO}_{4}$ after 28 days.

for control specimens in $\mathrm{H}_{2} \mathrm{SO}_{4}$ solution than sulfate exposure. Control specimens have shown UPV values from 4138 to $3675 \mu \mathrm{m} / \mathrm{sec}$, whereas all the geopolymer systems have shown UPV values greater than $4100 \mu \mathrm{m} / \mathrm{sec}$, respectively, indicating the good quality of the mortar specimens even after 4 weeks of exposure in acid medium. It is well evidenced from the photographs of Figures 11(a) and 11(b) that the surface of the cement mortar specimens has shown etching of the surface by the dissolution of $\mathrm{Ca}(\mathrm{OH})_{2}$ particles present in the cement. Over long cycles of exposure, ettringite is formed. [24]. Ettringite is no longer stable and decomposes into aluminium hydrates and gypsum and calcium silicate hydrate becomes unstable. The formation of gypsum (calcium sulphate) leads to softening of the mortar, but geopolymer mortars are highly stable and acid-resistant because of the inert materials present in the mortar.

\section{Conclusions}

From the above investigation, the following broad conclusions were drawn.

(1) Compressive strength test results indicated that alkali-activated RHA geopolymer mortars have shown superior performance to the control system. 


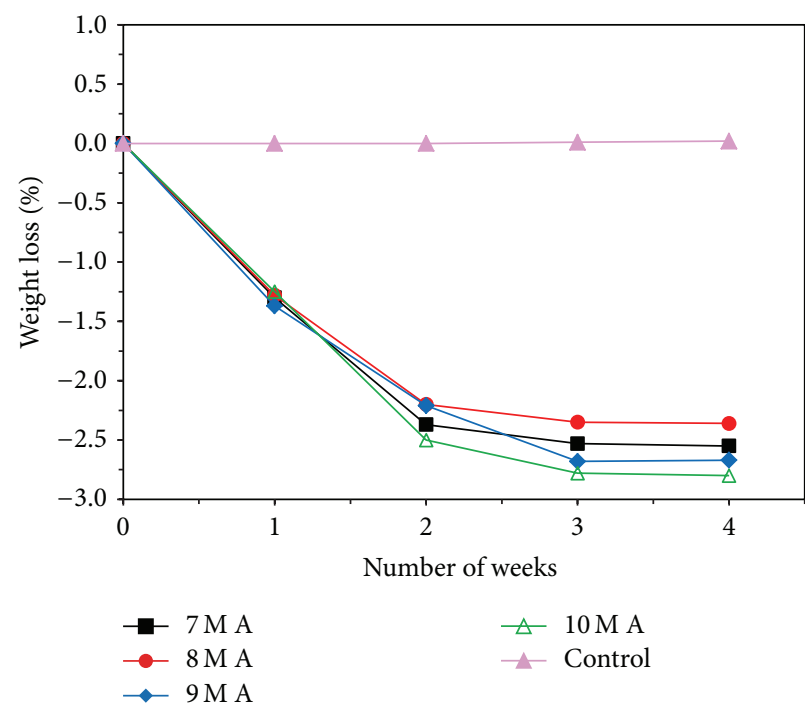

(a) Ambient curing

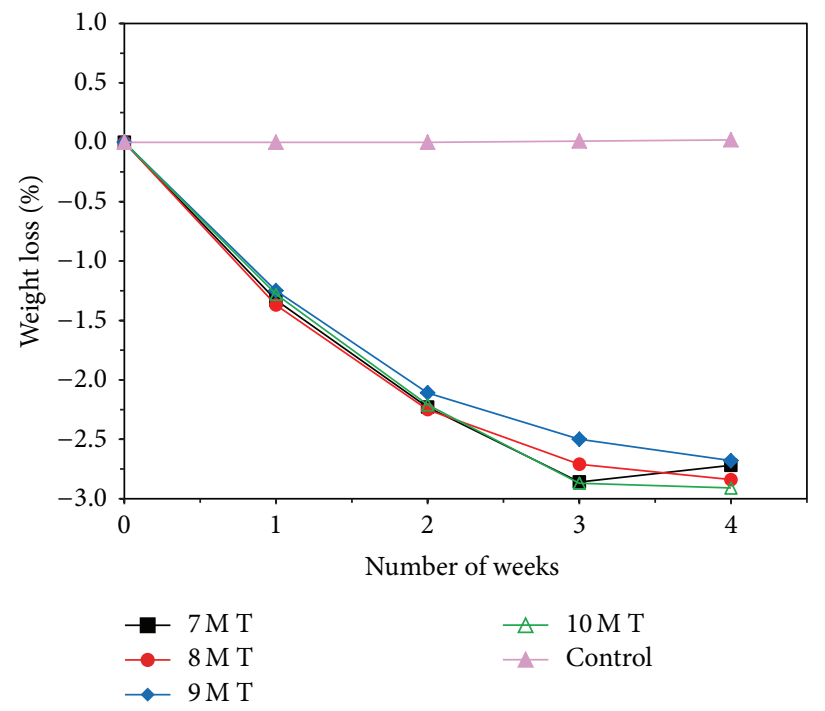

(b) Thermal curing

FIGURE 10: Weight loss for specimens immersed in $5 \% \mathrm{Na}_{2} \mathrm{SO}_{4}$ after 28 days.

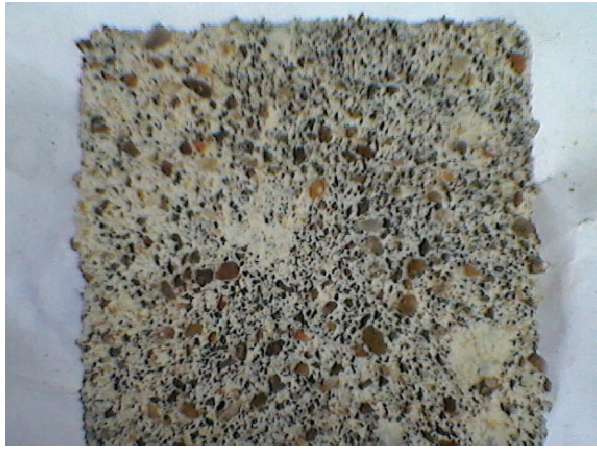

(a) Control mortar

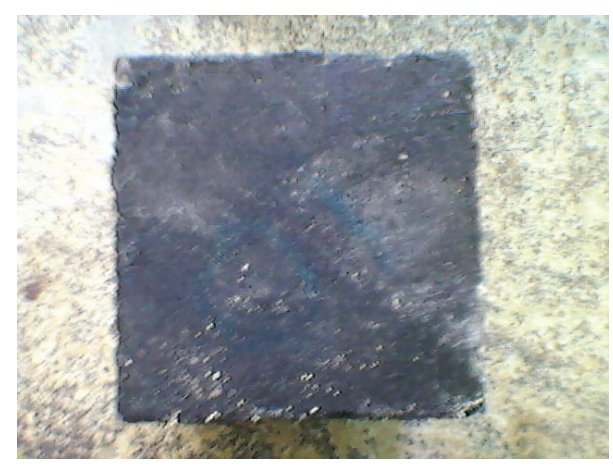

(b) Geopolymer mortar

FIGURE 11: Photograph of specimen immersed in $5 \% \mathrm{H}_{2} \mathrm{SO}_{4}$.

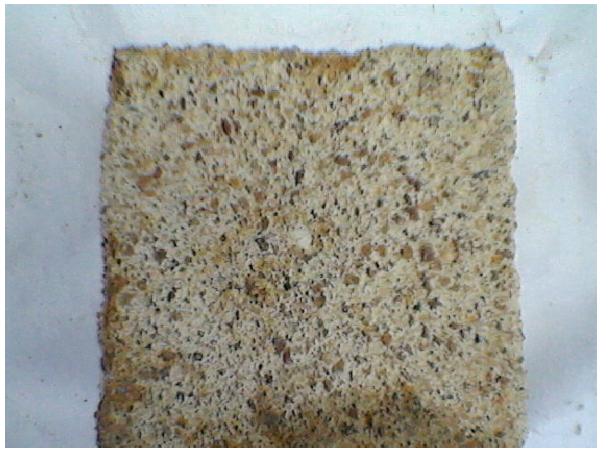

(a) Control mortar

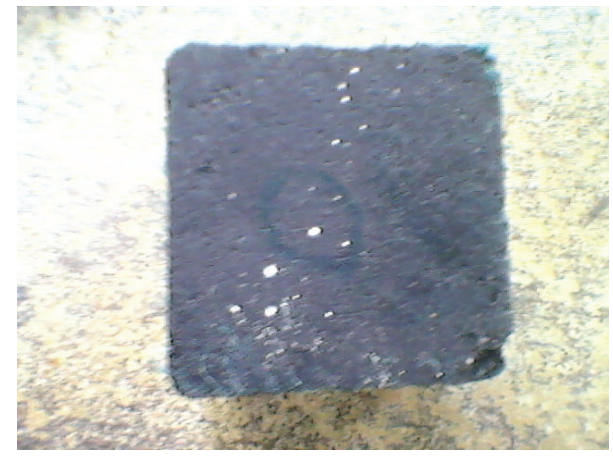

(b) Geopolymer mortar

FIgURE 12: Photograph of specimen immersed in 5\% $\mathrm{HCl}$. 


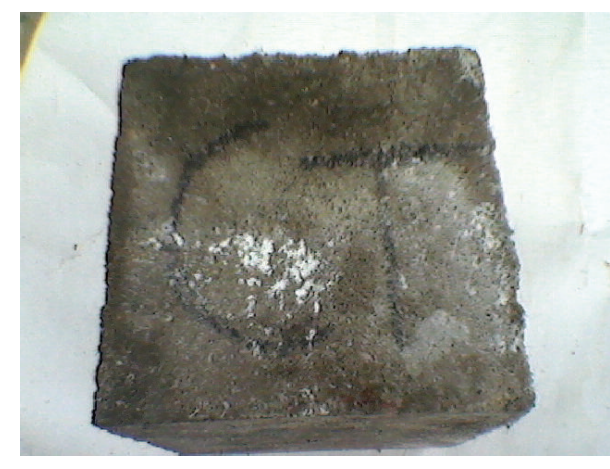

(a) Control mortar

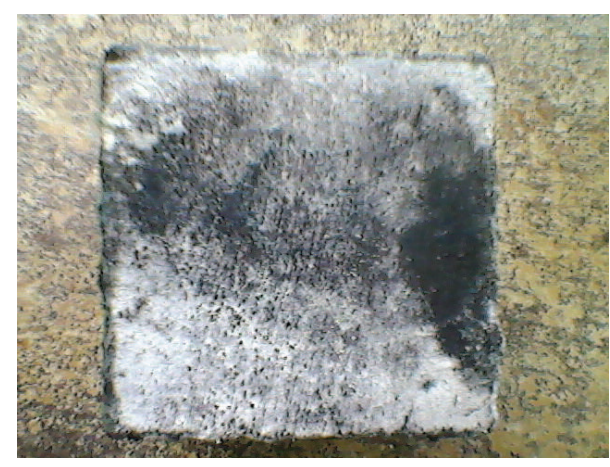

(b) Geopolymer mortar

FIgURE 13: Photograph of specimen immersed in $5 \% \mathrm{~N}_{2} \mathrm{SO}_{4}$.

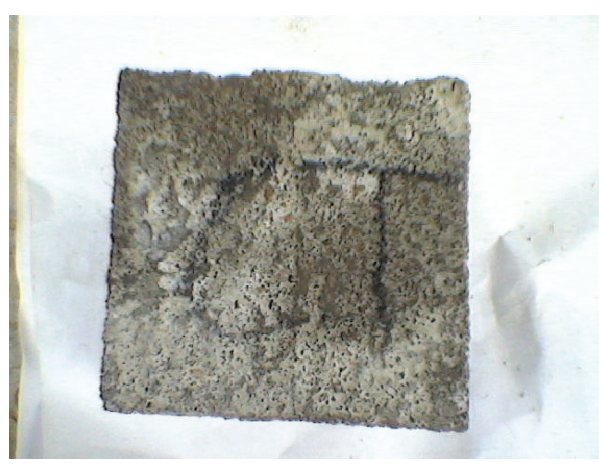

(a) Control mortar

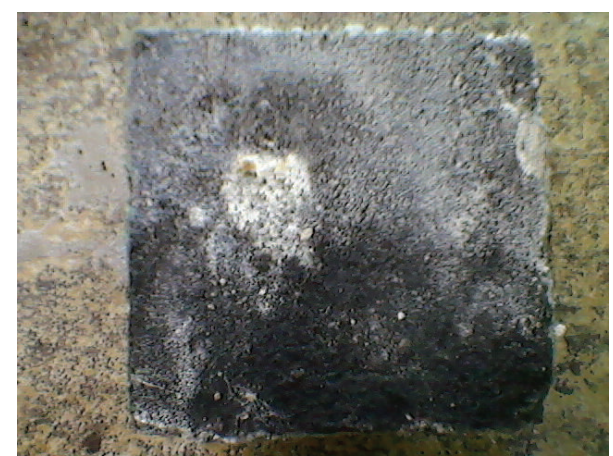

(b) Geopolymer mortar

FIgURE 14: Photograph of specimen immersed in $5 \% \mathrm{MgSO}_{4}$.

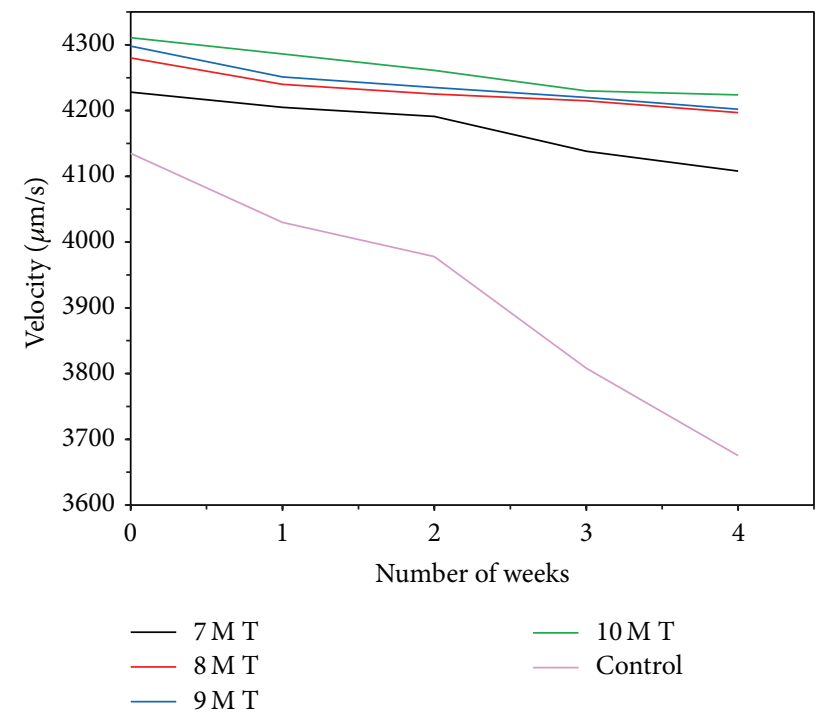

FIGURE 15: UPV for sulfuric acid.

(2) Fluorescent microscopy studies revealed that geopolymer mortars have denser, compact, and homogenous particle packing of the mortar.
(3) Capillary flow analysis indicated that geopolymer mortar has $55 \%$ reduction in pore diameter indicating the pore size refinement and pore blocking effect of the particles.

(4) Elevated temperature studies indicated that all the geopolymer mortars are more resistant to temperature up to 900 degrees.

(5) Acid immersion studies indicated that geopolymer mortars have shown better acid-resistant properties.

(6) By considering the various points obtained from this investigation, RHA can be used as a substitute material for OPC.

\section{Conflict of Interests}

The authors declare that there is no conflict of interests regarding the publication of this paper.

\section{Acknowledgment}

This research was supported by the Basic Science Research Program through the National Research Foundation of Korea (NRF) funded by the Ministry of Education (NRF2013R1A1A2060114). 


\section{References}

[1] D. L. Y. Kong and J. G. Sanjayan, "Damage behavior of geopolymer composites exposed to elevated temperatures," Cement and Concrete Composites, vol. 30, no. 10, pp. 986-991, 2008.

[2] V. M. Malhotra, "High-performance high volume fly ash concrete," ACI Concrete International, vol. 24, pp. 1-5, 2002.

[3] V. M. Malhotra, "Introduction: sustainable development and concrete technology," ACI Concrete International, vol. 2, p. 4, 2002.

[4] V. M. Malhotra, "Making concrete "greener" with fly ash," ACI Concrete International, vol. 21, pp. 61-66, 1999.

[5] B. V. Rangan, "Fly ash-based geopolymer concrete," in Proceedings of the International Workshop on Geopolymer Cement and Concrete, pp. 68-106, Allied Publishers Private Limited, Mumbai, India, December 2010.

[6] R. McCaffrey, "Climate change and the cement industry," Global Cement and Lime Magazine, pp. 15-19, 2002, (Environmental Special Issue).

[7] J. Davidovits, "High-alkali cements for 21st century concretes," in Concrete Technology: Past, Present, and Future: Proceedings of V. Mohan Malhotra Symposium, P. Kumar Metha, Ed., ACI SP-144, pp. 383-397, 1994.

[8] V. Saraswathy, S. Muralidharan, K. Thangavel, and S. Srinivasan, "Influence of activated fly ash on corrosion-resistance and strength of concrete," Cement and Concrete Composites, vol. 25, no. 7, pp. 673-680, 2003.

[9] V. Saraswathy and S. P. Karthick, "A state-of-the-art review on the durability of silica fume-blended concrete-a boon to the construction industry," Corrosion Reviews, vol. 31, no. 3-6, pp. 123-134, 2013.

[10] B. Lothenbach, K. Scrivener, and R. D. Hooton, "Supplementary cementitious materials," Cement and Concrete Research, vol. 41, no. 12, pp. 1244-1256, 2011.

[11] V. Saraswathy and H.-W. Song, "Electrochemical studies on the corrosion performance of steel embedded in activated fly ash blended concrete," Electrochimica Acta, vol. 51, no. 22, pp. 46014611, 2006.

[12] S. I. Khassaf, A. T. Jasim, and F. K. Mahdi, "Investigation on the properties of concrete containing rice husk ash to reduction the seepage in canals," International Journal of Scientific Technology Research, vol. 3, pp. 348-354, 2014.

[13] D. B. Raijiwala and P. H. S. Sankalp, "High performance green concrete," Civil Engineering and Architecture, vol. 1, pp. 1-6, 2013.

[14] A. Allahverdi and F. Škvára, "Acid corrosion of geopolymeric cementsî," in Proceedings of the 7th CANMET International Conference on Fly Ash, Silica Fume, Slag and Pozzolans in Concrete, vol. 2, pp. 561-579, 2001.

[15] A. Fernández-Jiménez, A. Palomo, and M. Criado, "Microstructure development of alkali-activated fly ash cement: a descriptive model," Cement and Concrete Research, vol. 35, no. 6, pp. 1204-1209, 2005.

[16] A. Kusbiantoro, M. F. Nuruddin, N. Shafiq, and S. A. Qazi, "The effect of microwave incinerated rice husk ash on the compressive and bond strength of fly ash based geopolymer concrete," Construction and Building Materials, vol.36, pp. 695-703, 2012.

[17] E. L. Foletto, M. M. Castoldi, L. H. Oliveira, R. Hoffmann, and S. L. Jahn, "Conversion of rice husk ash into zeolitic materials," Latin American Applied Research, vol. 39, no. 1, pp. 75-78, 2009.
[18] I. O. Yaman, G. Inci, N. Yesiller, and H. M. Aktan, "Ultrasonic pulse velocity in concrete using direct and indirect transmission," ACI Materials Journal, vol. 98, no. 6, pp. 450-457, 2001.

[19] M. A. M. Ariffin, M. A. R. Bhutta, M. W. Hussin, M. Mohd Tahir, and N. Aziah, "Sulfuric acid resistance of blended ash geopolymer concrete," Construction and Building Materials, vol. 43, pp. 80-86, 2013.

[20] S. Thokchom, P. Ghosh, and S. Ghosh, "Resistance of fly ash based geopolymer mortars in sulphuric acid," ARPN Journal of Engineering and Applied Sciences, vol. 4, pp. 65-70, 2009.

[21] D. L. Y. Kong and J. G. Sanjayan, "Effect of elevated temperatures on geopolymer paste, mortar and concrete," Cement and Concrete Research, vol. 40, no. 2, pp. 334-339, 2010.

[22] A. M. Rashad and S. R. Zeedan, "The effect of activator concentration on the residual strength of alkali-activated fly ash pastes subjected to thermal load," Construction and Building Materials, vol. 25, no. 7, pp. 3098-3107, 2011.

[23] O. A. Abdulkareem, A. M. Mustafa Al Bakri, H. Kamarudin, and I. Khairul Nizar, "Alteration in the microstructure of fly ash geopolymers upon exposure to elevated temperatures," Advanced Materials Research, vol. 795, pp. 201-205, 2013.

[24] E. K. Attiogbe and S. H. Rizkalla, "Response of concrete to sulfuric acid attack," ACI Materials Journal, vol. 85, no. 6, pp. 481$488,1988$. 

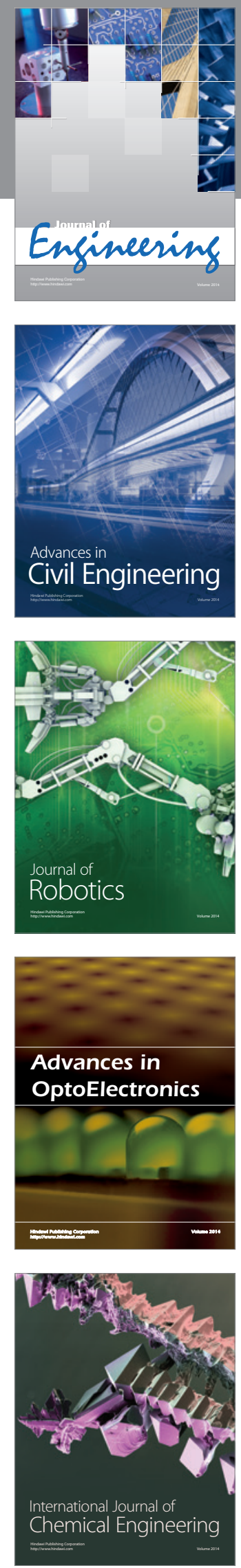

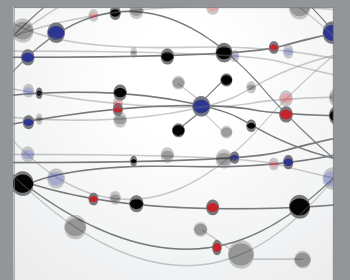

The Scientific World Journal
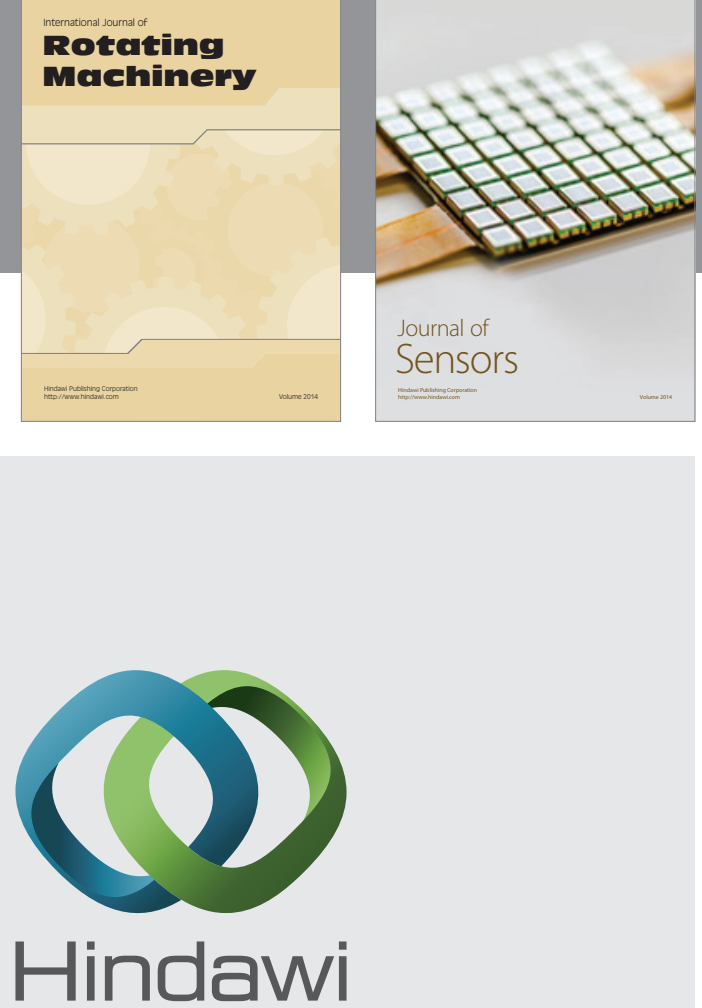

Submit your manuscripts at http://www.hindawi.com
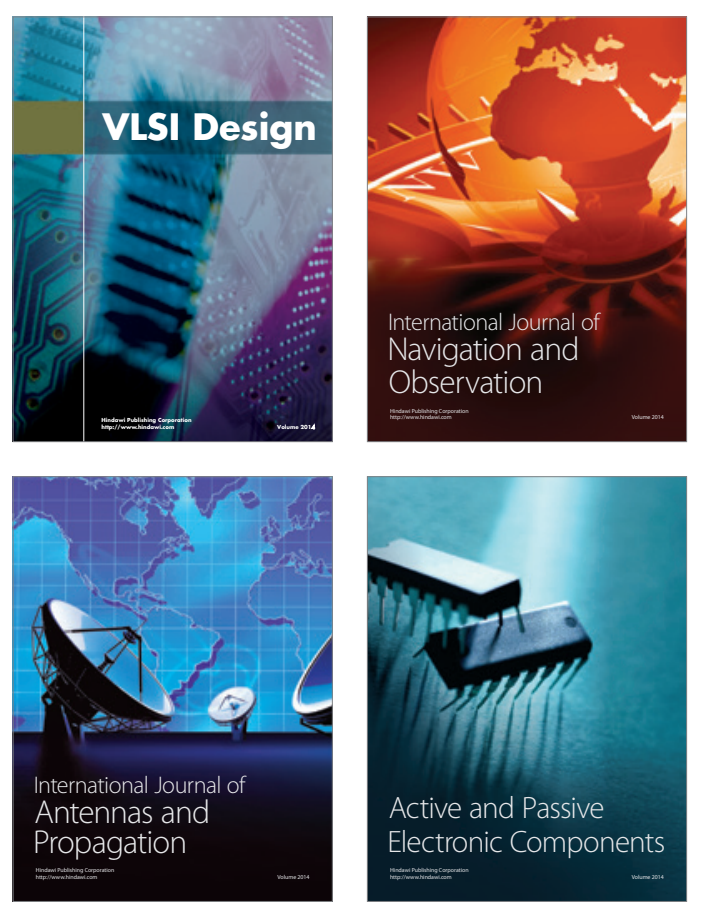
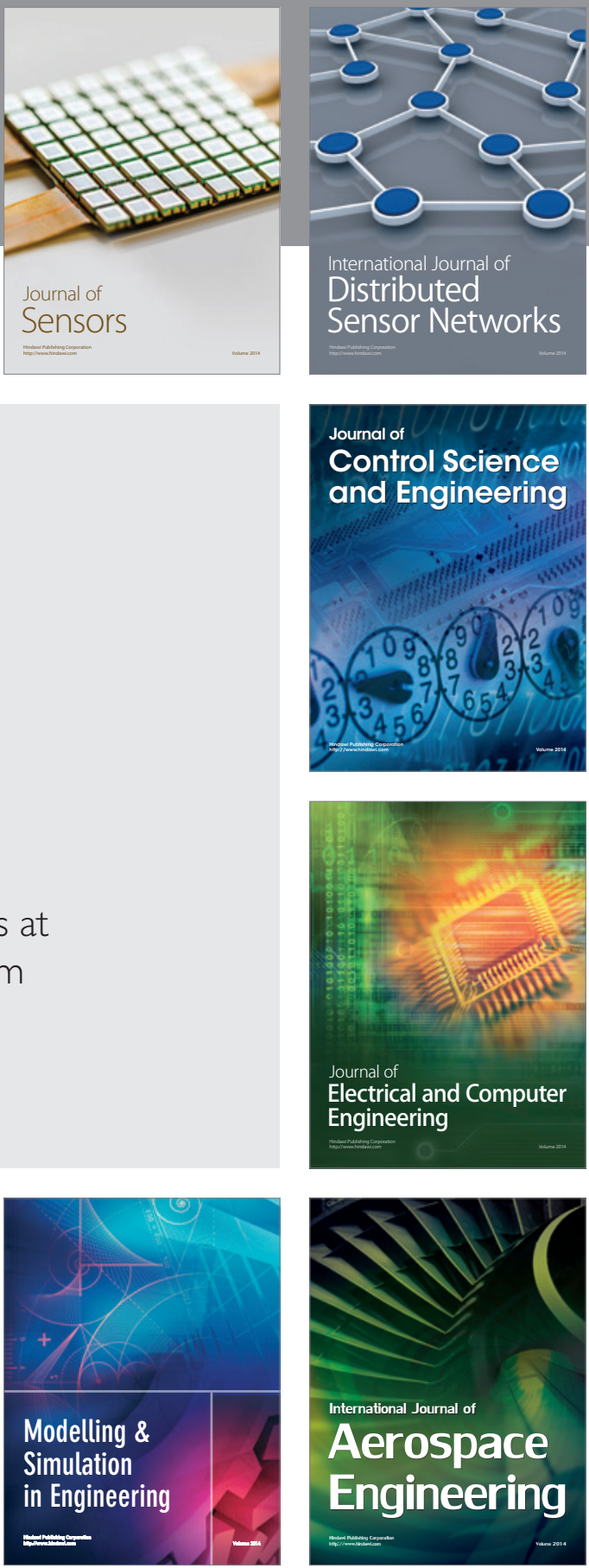

Journal of

Control Science

and Engineering
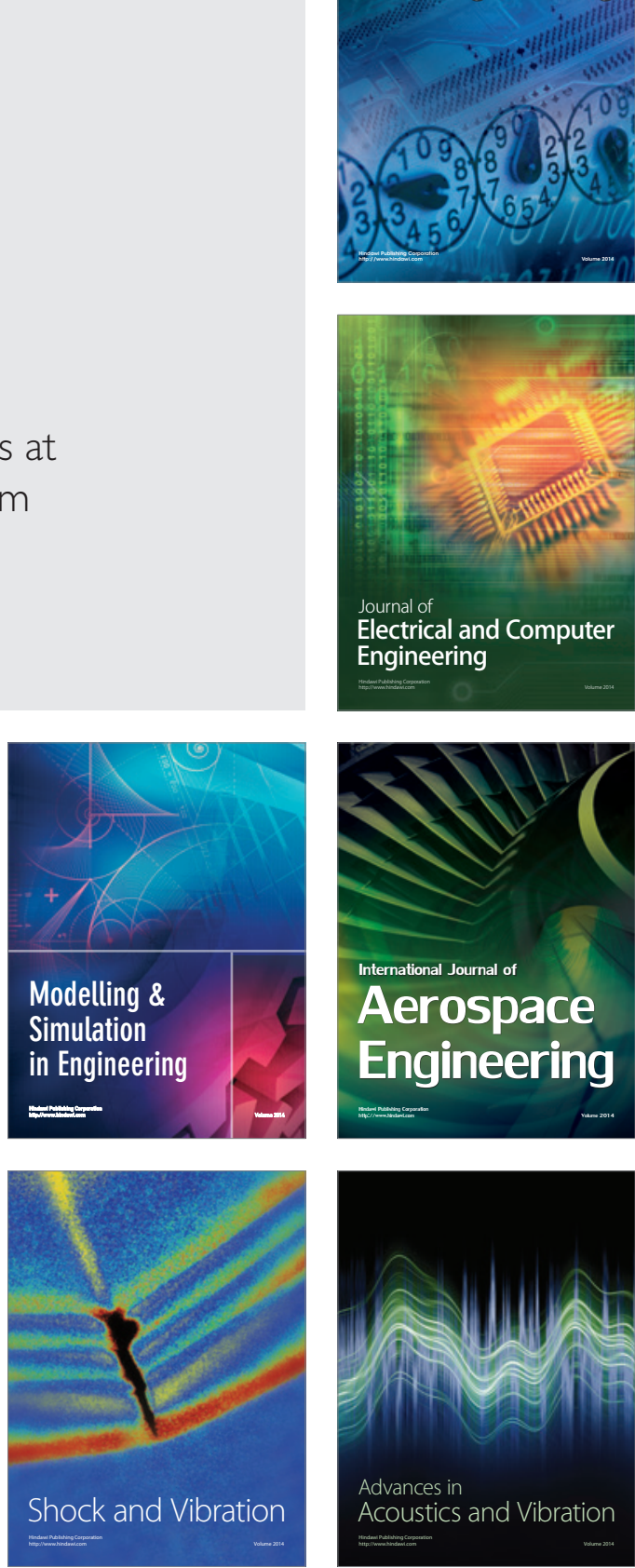